THURSDAY, MARCH I7, I870

\section{ON FLOATING MATTER AND BEAMS OF LIGHT}

$\mathrm{PEAMS}$ of light may be employed to reveal the existence of floating matter in the air; or the floating matter may be employed to reveal the track of the beams.

When the beam is intense it becomes an extremely powerful searcher and revealer of the state of the air. Thus examined, the air of a room which in diffuse daylight appears absolutely pure is seen to be loaded with suspended matter. Many of the fine clouds developed in my experiments on the action of light upon vapours disappear utterly in diffuse daylight; while when the room is darkened and the light of an intense beam confined to the clouds themselves, they appear highly luminous. The eye is the real re-agent here. Rendered sensitive by darkness, and receiving light from the floating matter alone, the amount of light competent to produce a sensible effect is incalculably small. The power of the light to make an impression is moreover increased by the extension given to the body which emits it.

The mobility of these actinic clouds is in some cases quite extraordinary. The differences of temperature introduced by the act of decomposition often cause the clouds to assume forms of astonishing complexity and beauty. The clouds which thus shape themselves by internal action are also exceedingly sensitive to external action. Supposing a thin actinic cloud to fill the experimental tube, the whole of it being flooded with the light of a beam passing longitudinally through the tube, an instant's contact of the tip of a spirit lamp flame with the under surface of the tube causes the cloud to break upwards in a violent current, and to whirl itself into the most beautiful vortices right and left of the vertical line. The rapidity with which the heat passes through the thick glass and sets the cloud in motion is surprising. The warmth of the finger suffices to produce an effect feebler than, but substantially the same, as that produced by the spirit lamp flame.

In fact, the floating matter of the air, properly illuminated, might be converted into a thermoscope of surpassing delicacy. A little brown paper smoke was diffused in an ordinary glass shade; the track of the beam through it was much whiter than through the air. Hence the invasion of the smokeless air could be instantly seen by the darkness it produced. On introducing the hand at the open base of the shade, a violent uprush of air immediately occurred. The smoke was violently whirled about, and the course of the whirlwinds distinctly marked by the relative action on the light of the smoky and the unsmoky air. I was not prepared to see so small a difference of temperature produce so large and prompt an effect.

Nor is it necessary to introduce dark extraneous air to render the currents through nebulous matter visible. The current produced in the actinic cloud by the spirit dame forms a dark vertical septum between the two adjacent parts of the cloud. When the current curls to form a cyclone, the septum curls also, producing dark spirals through the illuminated nebula.
The late Principal Forbes often referred to the floating scum on water slowly flowing through a channel; the lateral parts of which are retarded by friction. Such scum, or froth, arranges itself in distinct strix, separated from each other by comparatively free intervals. It is practically impossible to establish differential motions, either in solids or liquids, without producing some effect of this kind. Fibrous iron shows it ; while in the atmosphere differential currents produce cirrus clouds. I have often watched the way in which the suspended matter of the turbid Arve at Chamouni traced itself through the water. Notwithstanding the tossing endured from the source of the Arveyron downwards, the mixture of mud and liquid was by no means perfect. In fact, every new obstacle which introduced differential motion introduced also the striæ, and destroyed all uniformity of mixture.

Five or six weeks ago I had a square chamber constructed, the upper half of which is glazed, its floor consisting of transverse rails, over which is placed a thick mat of cotton wool. The chamber has a brass chimney, in which a rose burner can be lighted. An upward current is thus established in the chimney, the air below entering through the cotton-wool to supply the place of that discharged by the flame. When the chamber is filled with the ordinary laboratory air, a beam sent through it tracks its course on the floating matter. When the flame is ignited, the air enters through the cotton-wool; but the consequence is not a uniform enfeeblement of the light of the beam. Perfectly dark striæ pass through the luminous track, and they sometimes bend and whirl so as to form gracefully curved streams of darkness. Even air urged from the nozzle of a bellows through the luminous track, shows a tendency to form those striæ, though it, like the water of the Arve at Chamouni, is filled with the same floating matter as that of the air through which it is urged.

On a recent occasion the following effects were described, and an attempt was then made to explain them:-

In a cylindrical beam, which powerfully illuminated the dust of the laboratory, was placed an ignited spirit-lamp. Mingling with the flame, and round its rim, were seen wreaths of darkness resembling an intensely black smoke. On lowering the flame below the beam the same dark masses stormed upwards. They were at times blacker than the blackest smoke that I have ever seen issuing from the fumnel of a steamer, and their resemblance to smoke was so perfect as to lead the most practised observer to conclude that the apparently pure flame of the alcohol lamp required but a beam of sufficient intensity to reveal its clouds of liberated carbon.

But is the blackness smoke? This question presented itself in a moment. A red-hot poker was placed underneath the beam, and from it the black wreaths also ascended. A large hydrogen flame was next employed, and it produced those whirling masses of darkness far more copiously than either the spirit-flame or poker. Smoke was therefore out of the question.

What then was the blackness? It was simply that of stellar space; that is to say, blackness resulting from the absence from the track of the beam of all matter competent to scatter its light. When the flame was placed below the beam the floating matter was destroyed in situ; and the air, freed from this matter, rose into the beam, jostler aside the illuminated particles, and substituted for their light the darkness due to its own perfect transparency. Nothing could more forcibly illustrate the invisibility of the agent which renders all things visible. The beam crossed, unseen, the black chasm formed by the transparent air, while at both sides of the gap the thick-strewn particles shone out like a luminous solid under the powerful illumination. 
But here a difficulty meets us. It is not necessary to butn the particles to produce a stream of darkness. Without actual combustion, currents may be generated which shall exclude the floating matter, and therefore appear dark amid the surrounding brightness. I moticed this effect first on placing a red-hot copper ball below the beam, and permitting it to remain there until its temperature had fallen below that of boiling water. The dark currents, though much enfeebled, were still produced. They may also be produced by a flask filled with hot water.

To study this effect a platinum wire was stretched across the beam, the two ends of the wire being connected with the two poles of a voltaic battery. To regulate the strength of the current a rheostat was placed in the circuit. Beginning with a feeble current the temperature of the wire was gradually aug. mented, but before it reached the heat of ignition a flat stream of air rose from it, which when looked at edgeways appeared darker and sharper than one of the blackest lines of Fraunhofer in the solar spectrum. Right and left of this dark vertical band the floating matter rose upwards, bounding definitely the nonluminous stream of air. What is the explanation? Simply this. Tise hot wire rarefied the air in contact with it, but it did not equally lighten the floating matter. The convection current of pure air therefore passed upwards anong the particles, dragging them after it right and left, but forming between them an impassable black partition. In this way we render an account of the dark currents produced by bodies at a temperature below that of combustion.

This explanation has been found difficult. When the wire is white hot, it sends up a band of intense darkness. This, I say, is due to the destruction of the foating matter. But even when its temperature does not exceed that of boiling water the wire produces a dark ascending current. This, I say, is due to the distribution of the floating matter. The difficulty alluded to is probably to be referred to the brevity of the explanation. Imagine the wire clasped by the mote-filled air. My idea is that it heats the air and lightens it, without in the same degree lightening the floating matter. The tendency, therefore, is to start a current of clean air through the mote-filled air. Figure the motion of the air all round the wire. Looking at it transversely we should see the air at the bottom of the wire bending round it right and left in two branch currents, ascending its sides and turning to fill the partial vacuum created above the wire. Now as each new supply of air filled with its motes comes in contact with the hot wire, the clean air, as just stated, is first started through the inert motes. They are dragged after it, but there is a fringe of cleansed air in advance of the motes. The two purified fringes of the two branch currents unite above the wire, and, keeping the motes that once belonged to them right and left, they form by their union the dark band observed in the experiment. This process is incessant. Always the moment the mote-filled air touches the wire this distribution is effected, a permanent dark band being thus produced. Could the air and the particles under the wire pass through its mass we should have a vertical current of particles, but no dark band. For here, though the motes would be left behind at starting, they would hotly follow the ascending current and thus abolish the darkness.

It has been said that when the platinum wire is intensely. heated, the floating matter is not only distributed, but destroyed. Let this be proved. I stretched a wire about four inches long through the air of an ordinary glass-shade resting on its stand. Its lower rim rested on cotton wool, "which also surrounded the rim. The wire was raised to a white heat by an electric current. The air expanded, and some of it was forced through the cotton wool, while when the current was interrupted and the air within the shade cooled, the expelled air in its return did not carry motes along with it. At the beginning of this experiment the shade was charged with floating matter; at the end of half an hour it was optically empty.

On the wooden base of a cubical glass shade measuring eleven and a half inches a side, upright supports were fixed, and from one support to the other thirty-eight inches of platinum wire were stretched in four parallel lines. The ends of the platinum wire were soldered to two stout copper wires which passed through the base of the shade and could be connected with a battery. As in the last experiment the shade rested upon cotton wool. A beam sent through the shade revealed the suspended matter. The platinum wire was then raised to whiteness. In five minutes there was a sensible diminution of the matter, and in ten minutes it was totally consumed. This proves that when the platinum wire is sufficiently heated, the floating matter, instead of being distributed, is destroyed.

But is not the matter really of a character which permits of its destruction by the moderately heated platinum wire also? Here is the reply:-

I. A platinum tube with its plug of platinum gauze was connected with an experimental tube, through which a powerful beam could be sent from an electric lamp placed at its end. The platinum tube was heated till it glowed feebly but distinctly in the dark. The experimental tube was exhausted and then filled with air which had passed through the red-hot tube. A considerable amount of floating matter which had escaped combustion was revealed by the electric beam.

2. The tube was raised to brighter redness and the air permitted to pass slowly through it. Though diminished in quantity, a certain amount of floating matter passed into, the exhausted experimental tube.

3. The platinum tube was rendered still hotter; a barely perceptible trace of the floating matter now passed through it.

4 The experiment was repeated, with the difference that the air was sent more slowly through the red-hot tube. The floating matter was totally destroyed.

5. The platinum tube was now lowered until it bordered upon a visible red heat. The air sent through it still more slowly than in the last experiment carried with it a cloud of floating matter.

If then the suspended matter is destroyed by a bright red heat, much more is it destroyed by a flame whose temperature is vastly higher than any here employed. So that the blackness introduced into a luminous beam where a flame is placed beneath it is due, as stated, to the destruction of the suspended matter. At a dull red heat, however, and still more when only on the verge of redness, the platinum tube permitted the motes to pass freely. In the latter case the temperature was $800^{\circ}$ or $900^{\circ} \mathrm{Fahrenheit}$ This was unable to destroy the suspended matter; much less, therefore, would a platinum wire heated to $2 \mathrm{I} 2^{\circ}$ be competent to do so. Such a wire can only distribute the matter, not destroy it.

The floating dust-is revealed by intense local illumination. It is seen by contrast with the adjacent unilluminated space, the brighter. the illumination the more sensible is the difference. Now the beam ermployed in 
the foregoing experiments is not of the same brightness throughout its entire transverse section. Pass a white switch, or an ivory paper-cutter, rapidly across the beam, the impression of its section will linger on the retina. The section seems to float for a moment in the air as a luminous circle with a rim much brighter than its central portion. 'The core of the beam is thus seen to be enclosed by an intensely luminous sheath. An effect complementary to this is observed when the beam is intersected by the dark band from the platinum wire. The brighter the illumination, the greater must be the relative darkness consequent on the withdrawal of the light. Hence the cross section of the sheath surrounds the dark band as a darker ring.

The following four paragraphs, though printed nearly two months ago, have not been published hitherto. Might I say that whatever my opinion on the subject of "spontaneous generation" may be, I purposely abstain from expressing it here? That expression shall be given at the proper time. I desire now to show the practical value of the luminous beam as an investigator of the state of the air.

The question of "Spontaneous generation" is intimately connected with our present subject. On this point a kind of polar antagonism has long existed between different classes of investigators. Van Helmont gave a receipt for the manufacture of mice, and it was for ages firmly believed that the maggots in putrefying flesh were spontaneously produced. Redi, a member of the famous Academy del Cimento, destroyed this notion by proving that it was only necessary to protect the meat by a covering of gauze to prevent the reputed generation. In 1745 two very able men, Needham and Spallanzani, took opposite sides in the discussion, the forming affirming and the latter denying the fact of spontaneous generation. At the beginning of our own century, we find on the affirmative side Lamarck, Oken, and J. Miiller; and on the negative Schwann, Schultze, and Ehrenberg. The chief representatives of the two opposing parties in our day are Pouchet and Pasteur.

The method of inquiry pursued in this discourse will, I think, help to clear the field of discussion. The experimenters do not seem to have been by any means fully aware of the character of the atmosphere in which they worked; for if this had been the case, some of the experiments recorded would never have been made. For example, to make the destruction of atmospheric germs doubly sure, M. Pouchet, the distinguished supporter of the doctrine of spontaneous generation, burnt hydrogen ${ }^{*}$ in air and collected the water produced by the combustion. Even in this water he afterwards found organisms. But supposing he had seen, as you have, the manner in which the air is clouded with floating matter, would he have concluded that the deportment of water which had been permitted to trickle through such air could have the least influence in deciding this great question I think not. Here is a quantity of water produced and collected exactly as M. Pouchet produced and collected his. This water is perfectly clear in the common light; but in the condensed electric beam it is seen to be laden with particles, so thick-strewn and minute, as to produce a continuous cone of light. In passing through the air the water loaded itself with this matter, and hence became charged with incipient life.*

Let me now draw your attention to an experiment of Pasteur, which I believe perplexes some of the readers and admirers of that excellent investigator. Pasteur prepared twenty-one flasks, each containing a decoction of yeast, filtered and clear. $\mathrm{He}$ boiled the decoction, so as to destroy whatever germs it might contain, and while the space above the liquid was filled with pure steam he sealed his flasks with a blow-pipe. He opened ten of them in the deep, damp caves of the Paris Observatory, and eleven of them in the courtyard of the establishment. Of the former, one only showed signs of life subsequently. In nine out of the ten flasks no organisms of any kind were developed. In all the others organisms speedily appeared.

Now here is an experiment conducted in Paris, which shows

* In this case a polished silver basin was soldered to one end of a wide brass tube; the tube was filled with ice, the hydrogen flame was permitted to play upon the basin, and the water of condensation was then collected. Dr. Child also objects to Pouchet's experiment. that the air of one locality can develop life when the air of another locality cannot. Let us see whether we cannot here in London justify and throw light upon this experiment. I place this large flask in the beam, and you see the luminous track crossing it from side to side. The flask is filled with the air of this room, charged with its germs and its dust, and hence capable of illumination. But here is another similar flask, which cuts a clear gap out of the beam. It is filled with unfiltered air, and still no trace of the beam is visible. Why? By pure accident I stumbled on this flask in our apparatus room, and on inquiry learnt that it had been a short time previously taken out of one of the cellars below stairs. Other flasks were in the same cellar. I had three of them brought up to me; they were optically empty. The still air had deposited its dust, germs and all, and was itself practically free from suspended matter. You can now understand the impotence of the air of the Paris caves. The observation illustrates at once the influence of the germs and the accuracy of Pasteur.

The air of the cellar was afterwards examined by the electric lamp. Though less heavily charged than the air outside, it was by no means free from particles. This was to be expected, because the door of the cellar was frequently opened. The flasks themselves were the true tranquil chambers; on their sides the dust had been deposited, and to them it firmly clung. To prove this several flasks about ten inches in diameter were filled with common air, corked, and laid upon a table in the laboratory. After two days' quiet they were optically empty.

Nor is it necessary even to cork the flasks; for with their mouths open the air within them is scarcely disturbed, certainly not displaced. 'Two days' rest on one of the laboratory tables suffices to deposit the organic dust and to render the open flasks optically empty.

I have had a chamber erected with a view to experiments on this subject. The lower half is of wood, its upper half being enclosed by four glazed window-frames. The chamber tapers to a truncated cone at the top. It measures in plan $3 \mathrm{ft}$. by $2 \mathrm{ft}$. $6 \mathrm{in}$, and its height is $5 \mathrm{ft}$. Ioin. On the 6th of February this chamber was closed, and every crevice that could admit dust or cause displacement of the air was carefully pasted over with paper. The electric beam at first revealed the floating dust within the chamber as it did in the air of the laboratory. The chamber was examined almost daily; a perceptible diminution of the floating matter being noticed on each occasion. At the end of a week the chamber was optically empty, exhibiting no trace of matter competent to scatter the light. But where the beam entered, and where it quitted the chamber, the white circles stamped upon the interior surfaces of the glass showed what had become of the dust. It clung to those surfaces, and from them instead of from the air, the light was scattered. If the electric beam were sent through the air of the Paris Caves, the cause of its impotence as a generator of life would, I venture to predict, be revealed.

It cannot, I think, be doubted that the method of observation here pursued is destined to furnish useful control and guidance in researches of this nature.

Royal Institution, March I4

J. TYNDALL.

\section{HEREDITARY GENIUS}

Hereditary Genius, an Inquiry into its Laws and Consequences. By Francis Galton, F.R.S., \&c. (Macmillan \& Co.)

I N this book Mr. Galton proposes to show that a man's natural abilities are derived by inheritance, under exactly the same limitations as are the form and physical 